\title{
Correction to: Engraftment of bioengineered three-dimensional scaffold from human amniotic membrane-derived extracellular matrix accelerates ischemic diabetic wound healing
}

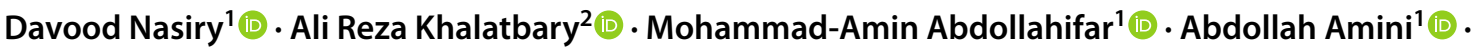 \\ Mohammad Bayat ${ }^{1}$ (D) $\cdot$ Afshin Noori $^{3}$ (I) . Abbas Piryaei ${ }^{1,3,4}$
}

Published online: 30 November 2021

○) Springer-Verlag GmbH Germany, part of Springer Nature 2021

\section{Correction to: Archives of Dermatological Research https://doi.org/10.1007/s00403-020-02137-3}

In this article two citations were missing in the following sentence which was present in the paragraph starting "To create wound, under general anesthesia...".

To create an ischemic wound model, two sagittal full skin thickness incisions ( $12 \mathrm{~cm}$ long) were created on the sides of the wound to cut off the sidelong blood supply (Fig. 1c-e) $[14,35]$.

\section{References}

14. Ebrahimpour-Malekshah R, Amini A, Zare F, Mostafavinia A, Davoody S, Deravi N, Rahmanian M, Hashemi SM, Habibi M, Ghoreishi SK, Chien S, Shafikhani S, Ahmadi H, Bayat S, Bayat M (2020) Combined therapy of photobiomodulation and adiposederived stem cells synergistically improve healing in an ischemic, infected and delayed healing wound model in rats with type 1

The original article can be found online at https://doi.org/10.1007/ s00403-020-02137-3.

\section{Abbas Piryaei}

piryae@sbmu.ac.ir

Davood Nasiry

davood1990nasiry@gmail.com

Ali Reza Khalatbary

Khalat90@yahoo.com

Mohammad-Amin Abdollahifar

m_amin58@yahoo.com

Abdollah Amini

d.amini2008@yahoo.com

Mohammad Bayat

bayat_m@yahoo.com

Afshin Noori

afshin_noori92@yahoo.com diabetes mellitus. BMJ Open Diabetes Res Care 8(1):e001033. https://doi.org/10.1136/bmjdrc-2019-001033 (PMID:32098898 ;PMCID:PMC7206914)

35. Moradi A, Zare F, Mostafavinia A, Safaju S, Shahbazi A, Habibi M, Abdollahifar MA, Hashemi SM, Amini A, Ghoreishi SK, Chien S, Hamblin MR, Kouhkheil R, Bayat M (2020) Photobiomodulation plus adipose-derived stem cells improve healing of ischemic infected wounds in type 2 diabetic rats. Sci Rep 10(1):1206. https://doi.org/10.1038/s41598-020-58099-z (PMID :31988386;PMCID:PMC6985227)

Publisher's Note Springer Nature remains neutral with regard to jurisdictional claims in published maps and institutional affiliations.
1 Department of Biology and Anatomical Sciences, School of Medicine, Shahid Beheshti University of Medical Sciences, 1985717443 Tehran, Iran

2 Department of Anatomy, Faculty of Medicine, Molecular and Cell Biology Research Center, Mazandaran University of Medical Sciences, Sari, Iran

3 Department of Stem Cells and Developmental Biology, Cell Science Research Center, Royan Institute for Stem Cell Biology and Technology, ACECR, Tehran, Iran

4 Urogenital Stem Cell Research Center, Shahid Beheshti University of Medical Sciences, Tehran, Iran 